\title{
Research on modified silicone compound photocatalyst by doping $\mathbf{N}$
}

\author{
DaWei Pan ${ }^{1}$, GuangXu Shao ${ }^{1}$ and QingWen Zhang ${ }^{2}$ \\ ${ }^{1}$ Department of Environmental Engineering, School of Chemical Engineering, University of Science and Technology Liaoning, Anshan, \\ Liaoning, China \\ ${ }^{2}$ Anshan Iron and Steel Group Engineering Technology Co., Ltd., Anshan, Liaoning, China
}

\begin{abstract}
In order to improve the visible light response and reaction efficiency of nitrogen-doped $\mathrm{TiO}_{2}$ set urea as nitrogen source, and silica gel as the load reagent adopt sol-gel method to prepare powder of nitrogen-doped $\mathrm{TiO}_{2}$ supported on $\mathrm{SiO}_{2}$, use equal volume impregnation method to load $\mathrm{MnO}_{2}$ on catalyst, and then obtain the composite photocatalyst after drying, and roasting .The prepared composite catalysts were characterized by XPS, TEM, SEM, XRD and other methods. Moreover, the photo-catalytic activity of the composite catalysts under visible-light region was tested, and the influences of nitrogen content and calcinations temperature on the photo-catalytic activity were investigated. The results show that:(1) the range of light response of modified composite catalyst was expanded from ultraviolet region to visible-light region, which results in high visible-light catalytic activity in the degradation of methyl orange.(2) Through the mechanism of photo-catalytic reaction and the treatment effect analysis, $\mathrm{MnO}_{2}$ as catalytic resulting $\mathrm{O}_{2}$ can be served as a good electronic capture agent and improve the reaction efficiency.(3)With the reduction of nitrogen content,and the increase of calcination temperature, the visible-light catalytic activity was weakened.(4) The activity of catalyst was reused six times, without significant reduction and had excellent efficiency and stability.
\end{abstract}

\section{Introduction}

With the increasingly serious energy shortage and environmental pollution, fanding the suitable photocatalyst to realize the effective utilization of solar energy, has become a hot issue in the field. Therefore, $\mathrm{TiO}_{2}$ with excellent catalytic performance attracts more attention in the environmental, [1] which has the advantages of low cost, good chemical stability, nontoxic,and no secondary pollution. But there are also shortcomings, e.g.,the forbidden band of $\mathrm{TiO}_{2}$ is wide $(\mathrm{Eg}=3.2 \mathrm{eV})$ and can only absorb UV-light; In addition, the hole and electron stimulated by light are easily compounded so as to reduce the photo-quantum efficiency ${ }^{[2-3]}$. Many domestic and international experts and scholars have tried to use the nonmetal ion doping method to extend the visible light absorption of $\mathrm{TiO}_{2}$, where nitrogen-doping can effectively hence the absorption of the catalyst in the visible-light region, as well as the efficiency of photo-catalytic oxidation ${ }^{[4]}$. $\mathrm{SiO}_{2}$ as the load reagent can effectively control the growth of $\mathrm{TiO}_{2}$ particles so as to get smaller size, and larger specific surface area, which can improve the separation performance, and make them inactivation to prolong the service life ${ }^{[5-6]}$. Researches show that quantum yield is the most important factor influencing treatment effect of photocatalyst, so improving the light quantum yield of photo-catalyst, promoting the separation of photongenerated carriers and reducing the recombination rate are key factors, in this paper, by preparing the nitrogen- doped $\mathrm{TiO}_{2} / \mathrm{MnO}_{2}$ supported on $\mathrm{SiO}_{2}$ composite photocatalyst the new ecological $\mathrm{O}_{2}$ resolved from hydrogen peroxide which are produced in the process of catalytic hydrolysis can be used as electron capture agent to effectively promote the separation of photon-generated carriers and to reduce its compound probability ${ }^{[7]}$. This kind of photo-catalyst has advantages of visible light response, and smaller and equally distributed particle size, and can efficiently restrain the compound of electronic - hole pairs, which greatly improve the treatment effect of the pollutants.

\section{Experiment}

\section{1 preparation of Nitrogen-Doped $\mathrm{TiO}_{2} / \mathrm{MnO}_{2}$ supported on $\mathrm{SiO}_{2}$ composite photo-catalyst}

The preparation was made as follow : After adjusting the $\mathrm{PH}$ value of Solution B $(10 \mathrm{~mL}$ of deionized water and 20 mLof anhydrous ethanol ) to about 2, dropwise add Solution $\mathrm{A}(10 \mathrm{~mL}$ of actic acid, $10 \mathrm{~mL}$ of dibutyl phthalate and $30 \mathrm{~mL}$ anhydrous erhanol ) into it with strong stirring, and then continue to strongly stir for 30 minutes after dropping, add different volumes of urea whose concentration is $1 \mathrm{~mol} / \mathrm{L}$ to the mixed Solution with $\mathrm{N} / \mathrm{Ti}$ molar ratio of $10 \%, 15 \%, 20 \%$ and $25 \%$ respectively, and continue to stir for 30 minutes, add a certain amount of $\mathrm{SiO}_{2}$ as load reagent and strongly stir for 60 minutes, stand and air dry the mixture at room temperature until it 
become xerogel and then grind it in agate mortar, calcine it in muffle furnace for 3hours at different temperature of $350{ }^{\circ} \mathrm{C}, 400{ }^{\circ} \mathrm{C}, 450{ }^{\circ} \mathrm{C}$ and $500{ }^{\circ} \mathrm{C}$ respectively, grind it again and screen it by standard sieve with 300 meshes, adopt the equal volume impregnation method to load a certain concentration of manganese nitrate on the calcined sample of catalyst in ultrasonic instrument, after 1 hour's drying, and calcination a series of nitrogendoped $\mathrm{TiO}_{2} / \mathrm{MnO}_{2}$ supported on $\mathrm{SiO}_{2}$ composite photocatalyst with different calcination temperature is obtained.

\section{2 performance of Nitrogen-Doped $\mathrm{TiO}_{2} / \mathrm{MnO}_{2}$ supported on $\mathrm{SiO}_{2}$ composite photo-catalyst}

The adsorption ability and photo-catalytic performance of nitrogen-doped $\mathrm{TiO}_{2} / \mathrm{MnO}_{2}$ supported on $\mathrm{SiO}_{2}$ composite photo-catalyst was evaluated by the degradation of methyl orange, and the reaction was carried out in the self-made additional stirring temperature cycle optical instrument with $150 \mathrm{w}$ iodine tungsten lamp as light source. The reaction device keeps the temperature of the reaction system at $25{ }^{\circ} \mathrm{C}$, and the magnetic stir keeps uniform concentration and temperature of solution in the system ,Take a certain quality of nitrogen-doped $\mathrm{TiO}_{2} / \mathrm{MnO}_{2}$ supported on $\mathrm{SiO}_{2}$ composite photo-catalyst in reaction device, add $100 \mathrm{~mL}$ of methyl orange solution with certain concentration, and make it adsorptiondesorption balance through 30 minutes' magnetic stirring under the condition of no light, and then turn on the iodine tungsten lamp for illumination. In the process of aphotic adsorption - desorption balance and illumination, take a sample every 20 minutes, use the principle of centrifugal separation to remove the photo-catalyst, adopt ultraviolet-visible spectrophotometer to measure the absorbance of supernatant fluid at the longest absorption wave, and then calculate the concentration according to the standard working curve based on the concentration $\left(C_{t}\right)$ of the supernatant fluid at the degradation time $(\mathrm{t})$ and the initial concentration $\left(\mathrm{C}_{0}\right)$ of degradation, calculat the degradation rate (D) of methyl orange to evaluate the photocatalytic activity of nitrogen-doped $\mathrm{TiO}_{2} / \mathrm{MnO}_{2}$ supported on $\mathrm{SiO}_{2}$ composite photo-catalyst:

$\mathrm{D}=\left(\mathrm{c}_{\mathrm{t}}-\mathrm{c}_{0}\right) / \mathrm{c}_{0} \times 100 \%$

\section{Results and Discussion}

\subsection{Characterization of Catalysts}

\subsubsection{X-ray diffraction (XRD) analysis of the catalyst}

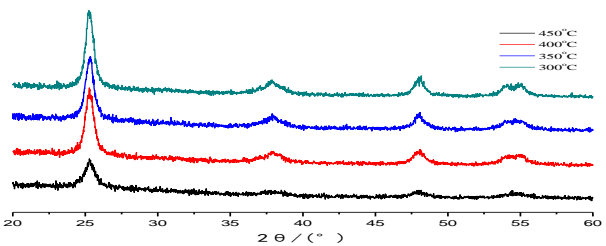

Figure1. The XRD spectrum of $20 \% \mathrm{~N}$ at different calcination temperatures
The X-ray diffraction (XRD) spectrum in Figure 1 shows that: all nitrogen doped $\mathrm{TiO}_{2} / \mathrm{MnO}_{2}$ supported on $\mathrm{SiO}_{2}$ composite photocatalysts with $\mathrm{N} / \mathrm{Ti}$ molar ratio of $20 \%$ prepared at $300^{\circ} \mathrm{C}, 350{ }^{\circ} \mathrm{C}, 400^{\circ} \mathrm{C}$ and $450^{\circ} \mathrm{C}$ respectively, are anatase phases, and the Ti-N diffraction peak does not appear, because high temperature made $\mathrm{N}$ volatilize, resulting in low $\mathrm{N}$ content, or larger $\mathrm{Ti}$ - $\mathrm{N}$ clusters fail to form in the complex catalyst; Meanwhile the movement of characteristic peak of anatase type $\mathrm{TiO}_{2}$ does not appear, because of nitrogen-doping, it shows that nitrogen doping does not change its crystal tructure. Using Scherrer formula to calculate the average particle size, the results are $13.8 \mathrm{~nm}, 14.6 \mathrm{~nm}, 12.3 \mathrm{~nm}$, and $17.2 \mathrm{~nm}$. With the increase of calcination temperature, the characteristic peak of anatase crystal phase becomes more keen-edged, which means the crystal shape is more and more regular and the size becomes larger and larger, because the increase of calcination temperature causes agglomeration of particles.

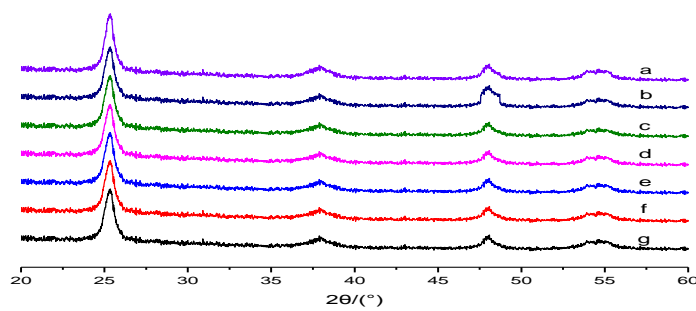

(a. $400{ }^{\circ} \mathrm{CTiO}_{2}$ b. $400{ }^{\circ} \mathrm{CTiO}_{2} / \mathrm{SiO}_{2}$ c. $400{ }^{\circ} \mathrm{CN} / \mathrm{TiO}_{2} \quad$ d. $400^{\circ} \mathrm{C}$ $10 \% \mathrm{~N} / \mathrm{TiO}_{2} / \mathrm{SiO}_{2} / \mathrm{Mn}^{2+}$ e. $400015 \% \mathrm{~N} / \mathrm{TiO}_{2} / \mathrm{SiO}_{2} / \mathrm{Mn}^{2+} \mathrm{f}$. $400{ }^{\circ} \mathrm{C} 20 \% \mathrm{~N} / \mathrm{TiO}_{2} / \mathrm{SiO}_{2} / \mathrm{Mn}^{2+}$ g. $400{ }^{\circ} \mathrm{C} 25 \% \mathrm{~N} / \mathrm{TiO}_{2} / \mathrm{SiO}_{2} / \mathrm{Mn}^{2+}$ )

Figure 2. XRD spectrum of nitrogen doped samples with different molar ratios at calcination temperature of $400^{\circ} \mathrm{C}$

Figure 2 shows that: all nitrogen-doped $\mathrm{TiO}_{2} / \mathrm{MnO}_{2}$ supported on $\mathrm{SiO}_{2}$ composite photo-catalysts with different $\mathrm{N} / \mathrm{Ti}$ molar ratio prepared at temperature of $400^{\circ} \mathrm{C}$ are anatase phases. Using the Scherrer formula to calculate the average grain size, the results are $9.1 \mathrm{~nm}$, $8.4 \mathrm{~nm}, 14.7 \mathrm{~nm}, 12.4 \mathrm{~nm}, 13.2 \mathrm{~nm}, 12.3 \mathrm{~nm}$, and $14.2 \mathrm{~nm}$. Nitrogen-doping enlarges the catalyst particles, and the size has a minimum value with the change of N/Ti molar ratio, which is corresponding to the catalyst with molar ratio of $20 \%$. It is consistent with the verification results according to theoretical basis that more keen-edged diffraction peak and smaller full width at half maximum means smaller particle and better crystal.

\subsubsection{Surface morphology analysis of Catalyst}

Scanning electron microscope (SEM) 


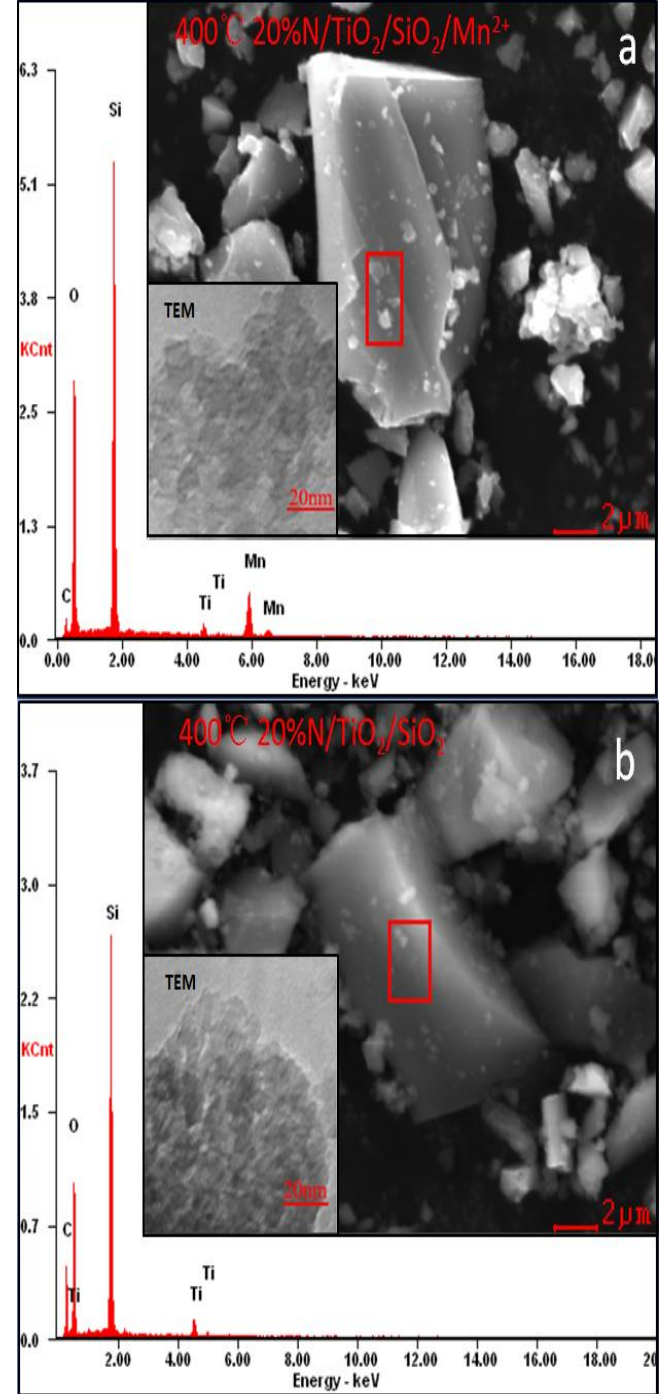

(a) $20 \% \mathrm{~N} / \mathrm{TiO}_{2} / \mathrm{SiO}_{2} / \mathrm{Mn}^{2+}$ (b) $20 \% \mathrm{~N} / \mathrm{TiO}_{2} / \mathrm{SiO}_{2}$

Figure 3. The SEM images of $\mathrm{TiO}_{2}$ photo-catalysts

Figure 3 is the SEM images and energy spectrum diagrams of nitrogen-doped $\mathrm{TiO}_{2}$ supported on $\mathrm{SiO}_{2}$ composite photocatalyst, to which $\mathrm{Mn}^{2+}$ is added. It can be seen from the figure: $\mathrm{TiO}_{2}$ particle size ranges from few nanometers to dozens of nanometers which is successfully loaded on the surface of $\mathrm{SiO}_{2}$ particle which relatively uniform distribution; the comparison of energy spectrum diagram shows that $\mathrm{Mn}^{2+}$ has been successfully incorporated into and loaded on the surface of $\mathrm{SiO}_{2}$, which slightly increases $\mathrm{TiO}_{2}$ particle size. Thus it shows $\mathrm{SiO}_{2}$ as loaded reagent can effectively improve the distribution of $\mathrm{TiO}_{2}$ particles, and enhance the dispersing performance; and the $\mathrm{Mn}^{2+}$ has been successfully incorporated and loaded on the surface of $\mathrm{SiO}_{2}$.

Transmission electron microscope (TEM)
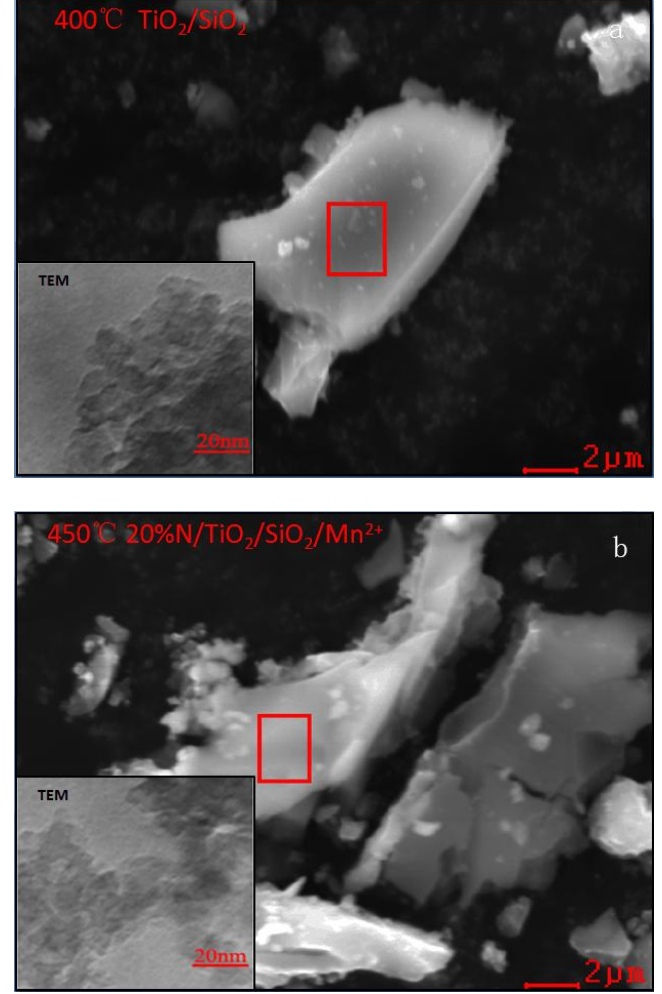

(a) $400^{\circ} \mathrm{C} \mathrm{TiO}_{2} / \mathrm{SiO}_{2}$ (d) $450^{\circ} \mathrm{C} 20 \% \mathrm{~N} / \mathrm{SiO}_{2} / \mathrm{TiO}_{2} / \mathrm{Mn}^{2+}$

Figure 4. TEM micrograghs of complex photo-catalyst

Figure 4 is the transmission electron microscope (TEM) images of different composition photo-catalysts. We can see from Figure 4 (a) that the $\mathrm{TiO}_{2}$ particles are uniformly distributed on the surface of $\mathrm{SiO}_{2}$, indicating that $\mathrm{SiO}_{2}$ loading can effectively improve the dispersibility of $\mathrm{TiO}_{2}$ particles; through the comparison of Figure 3 (a) and Figure 4 (b) it can be seen that the particle size increases with the increase of calcination temperature, which is due to the agglomeration of the grain caused by the increase of calcination temperature, verifying the analysis conclusion in XRD.

\subsubsection{UV-vis diffuse reflectance.}

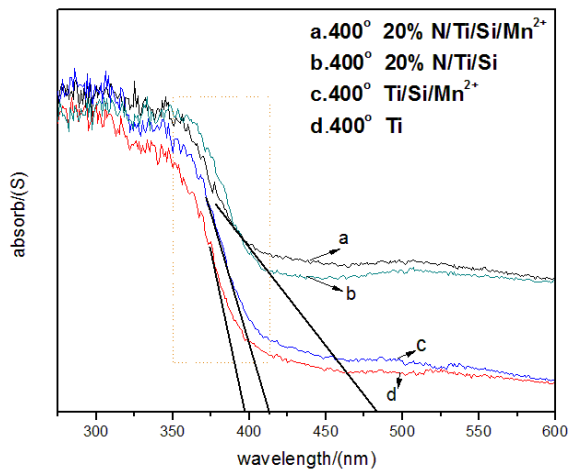

Figure 5 . UV-Vis Diffuse reflectance spectra of complex photo-catalyst 
The UV-Vis diffuse reflectance spectra of Fig. 5 show that the absorption range of the modified catalyst is extended to visible light region from $390 \mathrm{~nm}$ to $480 \mathrm{~nm}$, and the absorption wavelength range is increased by 90 $\mathrm{nm}$, which indicates that nitrogen doping can effectively improve the visible light response activity of the catalyst. According to the tangent comparison of the curves (c) and (d), the addition of $\mathrm{Mn}$ only enlarges the absorption range of the catalyst by about $20 \mathrm{~nm}$ (from $390 \mathrm{~nm}$ to 410 $\mathrm{nm}$ ). This shows that $\mathrm{Mn}$ is helpful to increase the number of photons involved in the photocatalytic reaction and enhance the absorption intensity of the composite photocatalyst, but does not produce obvious visible light response. According to the tangent comparison of curves a and (c), it is shown that doping $\mathrm{N}$ can effectively improve the visible light response activity of the catalyst, but Mn can not produce this effect. From the slope of the light absorption threshold region of the curves (a) and (d), the visible light response range of the composite photocatalyst is obviously enlarged, which indicates that the $\mathrm{N}_{2 \mathrm{p}}$ orbital replaces part of the $\mathrm{O}_{2 \mathrm{p}}$ orbital and forms a new hybrid orbital. The formation of Ti-O-N bonds on the surface of titanium dioxide forms a new energy level structure, which reduces the band gap of titanium dioxide and thus obtains visible light activity.

\subsubsection{X-ray photoelectron spectroscopy of Catalyst}

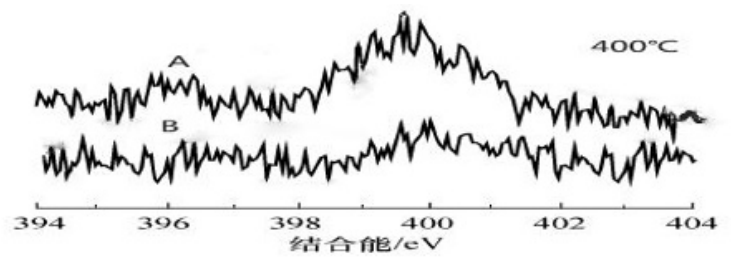

Figure 6. XPS energy spectrum diagram of $\mathrm{N}_{1 \mathrm{~s}}$ of $\mathrm{TiO}_{2}$ photocatalyst at calcination temperature of $400^{\circ} \mathrm{C}$

Figure 6 is the XPS energy spectrum diagram of composite catalysts at calcination temperature of $400{ }^{\circ} \mathrm{C}$, where $\mathrm{A}$ and $\mathrm{B}$ respectively represent the catalysts with and without nitrogen-doping. It can be seen from the figure that, for the nitrogen-doped catalyst samples, there is a new $\mathrm{N}_{1 \mathrm{~s}}$ peak at $396.1 \mathrm{eV}$, and a $\mathrm{N}_{1 \mathrm{~s}}$ peak of the catalyst surface adsor bed $\mathrm{N}_{2}$ at $401.7 \mathrm{eV}$, thus the $\mathrm{N}$ atoms and $\mathrm{TiO}_{2}$ molecules are combined by chemical bonds. Asahi ${ }^{[8]}$ et al, attributed the peak appearing in the $396 \mathrm{eV}$ to $\mathrm{N}$ atoms mixed with the crystal lattice, and attributed peaks appearing in the $400 \mathrm{eV}$ and $402 \mathrm{eV}$ to the molecular adsorption of $\mathrm{N}_{2}$ on the catalyst surface. They pointed out that the catalyst with visible light activity is associated with the $\mathrm{N}$ atoms, and this is because the hybridization of $\mathrm{N}_{2 p}$ orbital and $\mathrm{O}_{2 p}$ orbital happened, which can decrease the forbidden band width of $\mathrm{TiO}_{2}$, so as to be motivated by the visible light.

\subsection{Photo-catalytic activity of Nitrogen-Doped $\mathrm{TiO}_{2} / \mathrm{MnO}_{2}$ supported on $\mathrm{SiO}_{2}$ composite photo- catalyst}
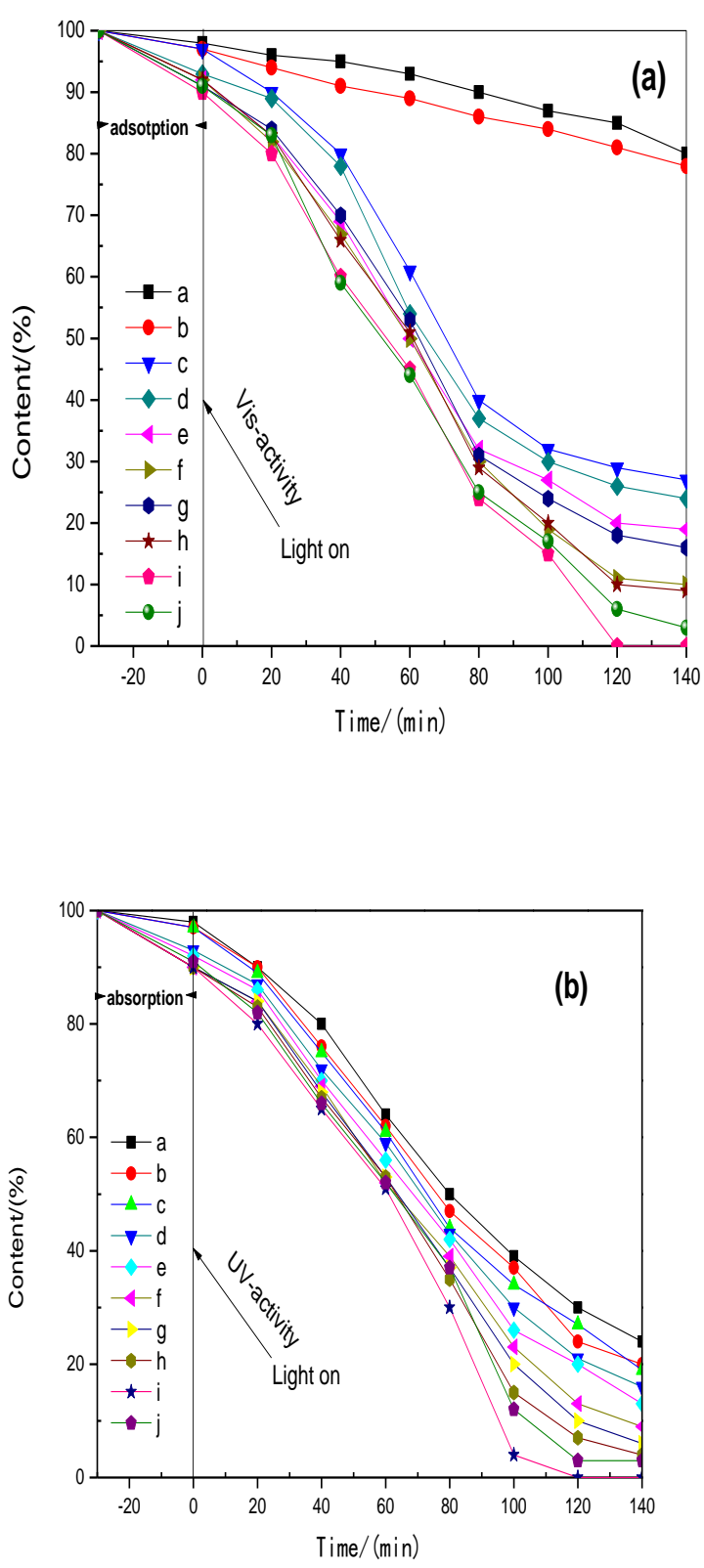

(1)Visible light (2) Uv light)(a. $400^{\circ} \mathrm{CTiO}_{2}$ b. $400^{\circ} \mathrm{CTiO}_{2} / \mathrm{SiO}_{2}$ c. $300{ }^{\circ} \mathrm{C} 20 \% \mathrm{~N} / \mathrm{TiO}_{2} / \mathrm{SiO}_{2} / \mathrm{Mn}^{2+}$ d. $400{ }^{\circ} \mathrm{C} 20 \% \mathrm{~N} / \mathrm{TiO}_{2} / \mathrm{SiO}_{2}$ e. $350{ }^{\circ} \mathrm{C} 20 \% \mathrm{~N} / \mathrm{TiO}_{2} / \mathrm{SiO}_{2} / \mathrm{Mn}^{2+}$ f. $40010 \% \mathrm{~N} / \mathrm{TiO}_{2} / \mathrm{SiO}_{2} / \mathrm{Mn}^{2+}$ g. $400{ }^{\circ} \mathrm{C} 15 \% \mathrm{~N} / \mathrm{TiO}_{2} / \mathrm{SiO}_{2} / \mathrm{Mn}^{2+}$ h. $4500^{\circ} \mathrm{C} 20 \% \mathrm{~N} / \mathrm{TiO}_{2} / \mathrm{SiO}_{2} / \mathrm{Mn}^{2+}$ i. $40020 \% \mathrm{~N} / \mathrm{TiO}_{2} / \mathrm{SiO}_{2} / \mathrm{Mn}^{2+}$ j. $40025 \% \mathrm{~N} / \mathrm{TiO}_{2} / \mathrm{SiO}_{2} / \mathrm{Mn}^{2+}$ )

Figure 7. The photo-catalytic activity of $\mathrm{TiO}_{2}$ under different conditions

Figure 7 (1) shows test results of visible-light activity of catalyst. The comparison between $d$ and $a / b$ shows that the catalytic activity of visible light of nitrogen-doped $\mathrm{TiO}_{2} / \mathrm{SiO}_{2}$ has been significantly improved. This is because the doped $\mathrm{N}$ atoms partly replaced $\mathrm{O}$ atoms enter into crystal lattice of $\mathrm{TiO}_{2}$, and formed an independent $\mathrm{N}_{2 \mathrm{p}}$ narrowband above the valence band, causing the response of composite catalysts to the visible light ${ }^{[8]}$. It can be seen from $\mathrm{f}, \mathrm{g}, \mathrm{i}$ and $\mathrm{j}$ in the figure, the catalytic activity of the composite photo-catalysts gradually 
increases with the increment of nitrogen-doping content, It will be optimal when the percentage of nitrogen doping content is $20 \%$, at this moment the composite catalyst can completely get rid of methyl orange within 120 minutes, and that with different doping amount will not have the same effect under the same conditions. The reason may be that the newly created energy level after nitrogendoping and the bulk phase of $\mathrm{TiO}_{2}$ form a compound semiconductor structure, hence the electric potential difference of both valence bands can make the hole of $\mathrm{TiO}_{2}$ 's valence band migrate to the newly formed energy levels, so as to effectively reduce the recombination probability of photo-generated electron hole, and improve the activity of catalyst ${ }^{[6]}$. can be seen from $I$ and $h$ in the figure that the removal rate decreases with the increase of temperature, and the reason may be that under high temperature, $\mathrm{N}$ element was oxidized and volatilizated in the heating process, leading to the decrease of $\mathrm{N}$ content in $\mathrm{TiO}_{2}$ lattice, and the enlargement of size, and decrease of specific surface area, can also lower the activity of visible-light response. Figure 6(1) shows the catalyst activity test results of UV-light. It can be seen from the figure that the composite catalyst in ultraviolet region also has a good degradation effect. simultaneously, Figure 7 shows, $\mathrm{Mn}^{2}+$ has obviously improved the processing efficiency of catalyst. This is because the $\mathrm{Mn}^{2}$ ${ }^{+}$is oxidized into $\mathrm{MnO}_{2}$ through calcination and loads on the surface of catalyst. It is used as catalyst to catalyze $\mathrm{H}_{2} \mathrm{O}_{2}$ to_produce $\mathrm{O}_{2}$ which is served as electron capture agent to effectively promote the separation of photogenerated carrier and reduces its compound probability.

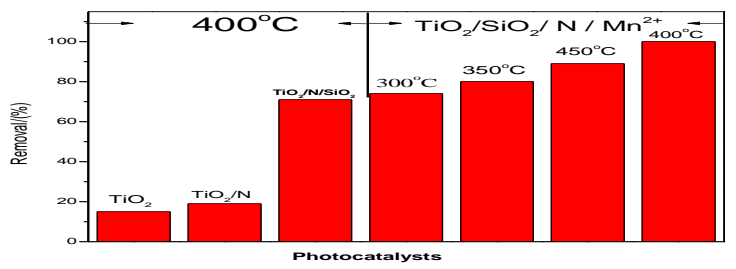

Figure 8. Photo-catalytic activity of $\mathrm{TiO}_{2}$ with different condition of $\mathrm{Mn}^{2+}$ under Visible light

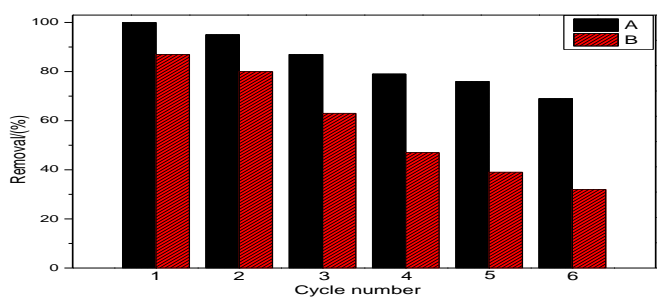

$$
\begin{gathered}
\left(\mathrm{A} .400{ }^{\circ} \mathrm{C} 20 \% \mathrm{~N} / \mathrm{TiO}_{2} / \mathrm{SiO}_{2} / \mathrm{Mn}^{2+}\right. \\
\mathrm{Mn}^{2+} \text { ) }
\end{gathered}
$$

Figure 9 Effect of run times on the photo-catalytic activity of $\mathrm{TiO}_{2}$

Figure 9 shows the experimental results of repeated use of catalyst. Under the same cycle times, the catalytic activity of the composite catalyst adding $\mathrm{SiO}_{2}$ as lode reagent is obviously higher. After reused six times, the degradation rate of composite catalyst is $75 \%$, while that without $\mathrm{SiO}_{2}$ is only $27 \%$ under the same condition. In conclusion, $\mathrm{SiO}_{2}$ as load reagent can effectively inhibit the deactivation of catalyst, so as to improve its service life.

In conclusion, for nitrogen-doped $\mathrm{TiO}_{2} / \mathrm{MnO}_{2}$ supported on $\mathrm{SiO}_{2}$ composite photo-catalyst, nitrogendoping can expand the range of light response of $\mathrm{TiO}_{2}$ and improve the activity in visible and ultraviolet region. $\mathrm{SiO}_{2}$ as load reagent has smaller particle size, and larger specific surface area, which can improve the separation performance of catalyst, so as to prolong the service life of catalyst. The mechanism shows that holes migrating to the surface of the semiconductor $\mathrm{TiO}_{2}$ react with $\mathrm{H}_{2} \mathrm{O}$ or $\mathrm{OH}^{-}$absorbing on the surface and the generated $\cdot \mathrm{OH}$, is free radical with strong oxidability, which can oxidize a variety of organic pollutants, and plays a main role in photo-catalytic system as oxidizing agent. The $\mathrm{Mn}^{2+}$ is oxidized into $\mathrm{MnO}_{2}$ by calcination, which loads on catalyst surface, and catalyzes $\cdot \mathrm{OH}$. The generated $\mathrm{O}_{2}$ can react with electrons which migrate to the surface of the semiconductor $\mathrm{TiO}_{2}$ to generate $\cdot \mathrm{O}_{2}$, and other activeoxygen free radicals. The reactive group will also be able to participate in oxidation-reduction reactions, and the generated $\mathrm{O}_{2}$ is served as electron capture agent to promote the separation of photo-generated carrier and reduce the recombination probability, which significantly improve the photo-catalytic activity of the catalyst. At the same time, according to the reaction dynamics, this process can promote the generation of $\mathrm{OH}$ which is served as the capture agent of hole.

\subsection{Photocatalytic reaction mechanism diagram}

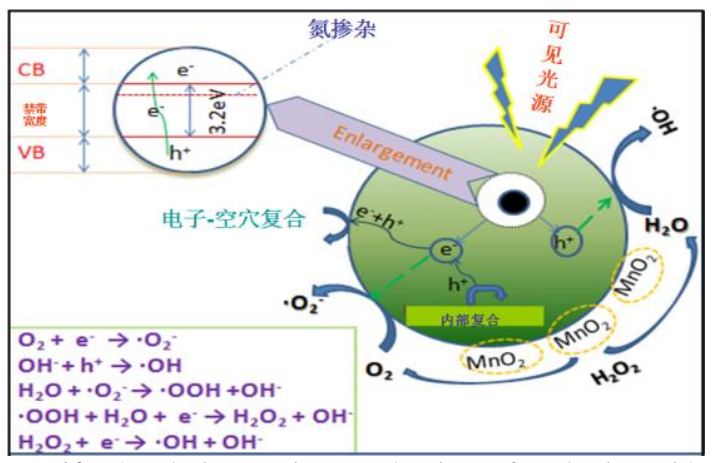

Figure 10. Catalytic reaction mechanism of $\mathrm{N}$-doping $\mathrm{TiO}_{2} / \mathrm{Mn}$ $\mathrm{O}_{2}$ load on $\mathrm{SiO}_{2}$ composite photo-catalyst

According to the simulated catalytic reaction mechanism of Fig. 10, the $\mathrm{N}_{2 \mathrm{p}}$ orbital and $\mathrm{O}_{2 \mathrm{p}}$ orbital in the bulk phase of $\mathrm{TiO}_{2}$ were hybridized by nitrogen doping, thus the width of the forbidden band of $\mathrm{TiO}_{2}$ was reduced and therefore could be excited by visible light. Electrons and holes migrate to the surface of catalyst particles under the action of electric field or through diffusion to react with the adsorbed substances on the surface. Holes are usually trapped by $\mathrm{OH}^{-}$and surface-adsorbed $\mathrm{H}_{2} \mathrm{O}$ molecules to form $\mathrm{OH}$, and hydroxyl radicals are the main active substances in photocatalysis. Electrons are usually trapped by $\mathrm{O}_{2}$ molecules adsorbed on the surface of 
particles, resulting in free radicals such as $\mathrm{O}_{2}, \mathrm{OOH}$, which can participate in many redox processes. Electronhole recombination is the most important reason for the serious decrease of reaction efficiency. Electron-hole recombination is very fast, but the rate of trapping carriers is relatively slow. Electrons are more active than holes. Therefore, $\mathrm{O}_{2}$ produced by high temperature oxidation of $\mathrm{Mn}^{2+}$ to $\mathrm{MnO}_{2}$ is used as electron trapping agent in advance. Adsorption on the catalyst surface is very important, it can improve the surface electron migration rate to inhibit carrier recombination, thereby increasing the quantum efficiency of photocatalytic reaction, but also promote the formation of hydrogen peroxide molecules adsorbed on the catalyst surface. Therefore, the prepared composite catalyst can achieve visible light response and obtain high treatment effect.

\section{Conclusions}

Make full use of the good performance of visible-light response of nitrogen doped $\mathrm{TiO}_{2}$, great adsorption of $\mathrm{SiO}_{2}$ and excellent catalytic activity of $\mathrm{MnO}_{2}$, through the effective combination of sol-gel method ${ }^{[9]}$ and incipientwetness impregnation method to prepare nitrogen-doped $\mathrm{TiO}_{2} / \mathrm{MnO}_{2}$ supported on $\mathrm{SiO}_{2}$ composite photo-catalyst. The results show that the urea in the form of $\mathrm{N}$ atom replaces $\mathrm{O}$ atoms in the $\mathrm{TiO}_{2}$ lattice, form $\mathrm{Ti}-\mathrm{O}-\mathrm{N}$ bong on the surface of $\mathrm{TiO}_{2}$, and constitute the new energy level structure, which made the absorption of catalyst cause red-shift and induce the visible light response, while the composite catalysts in both the ultraviolet and visible region show higher catalytic activity. $\mathrm{SiO}_{2}$ as load reagent can not only control the growth of $\mathrm{TiO}_{2}$ particles, to get smaller size and larger specific surface area, but also improve the separation performance of catalyst, so as to expend its service life. The $\mathrm{Mn}^{2+}$ is oxidized to $\mathrm{MnO}_{2}$ and loads on catalyst surface to make $\mathrm{O}_{2}$ which migrated to the surface of the semiconductor $\mathrm{TiO}_{2}$ as electron capture agent to promote the separation of photogenerated carrier and reduce the recombination probability. Then the generated active oxygen free radicals participate in oxidation-reduction reaction of dye pollutants to make them degrade, which significantly improves the photo-catalytic activity of the catalyst.

\section{References}

[1]Vinodgopal, Kam. EnvironmentalScience.Technology, $293: 841-845(1995)$

[2]J.W. J i, W.H. Ma, Y.P. Huang, etc. Chinese Science Bulletin,48 21 : 2199-2204(2003)

[3]W.H. Yuan, H.Q. Bi, C.H. Wei. Journal of south China university of technology, 323 :29-32( 2004)

[4]S. Yi , H. Yamaki, Q. W. Zhang, et. Solid State Ionics, 172 1-4 :205 209(2004)

[5]C.H. Ao, S.C. Lee. Appl.Catal.B:Environ, 443 :191205(2003)

[6]X.Y. Chen, S.L. Liu, X. Chen, et . Acta,Phys.Chim.Sin. 225 :517-522(2006)

[7]W.Y. Choi , et. .J.Phys.Chem. , 98:1369-1379(1994)

[8]Asahi R, Morikawa T, Ohwaki T, et al.Science, 293 5528 :269-271(2001)

[9]Burda. C, Y. Lou, X. Chen, et. Nano Letters 38 :10491051(2003)

[10]D.M.Shi,Z.X.Li,J.H.Duo. Environmental Science and Technology. 9:46-4(2002) 